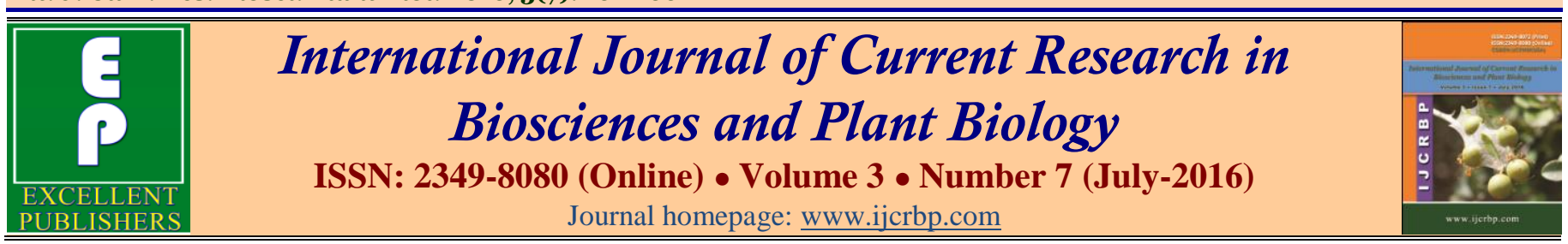

\title{
Impact of Different Carbon Sources, Tri-calcium Phosphate and Auxins on In Vitro Multiplication of Rhizophagus irregularis
}

\author{
B. Mohan Raj ${ }^{1,2 *}$, R. Bharath Kumar3, G. Venkata Rao ${ }^{1}$ and K. Sri Rama Murthy ${ }^{1}$ \\ ${ }^{1} R$ \& D Center for Conservation Biology and Plant Biotechnology, Shivashakti Biotechnologies Private Limited, S.R. Nagar, \\ Hyderabad-500 o38, Telangana State, India \\ ${ }^{2}$ Department of Biotechnology, Acharya Nagarjuna University, Guntur-522 510, Andhra Pradesh, India \\ 3Department of Biotechnology, Vignan University, Guntur-522 213, Andhra Pradesh, India
}

*Corresponding author.

\begin{abstract}
A b stract
In the present study, effect of different combinations and concentrations of carbon source, tri-calcium phosphate and auxins on in vitro multiplication of Rhizophagus irregularis was investigated and rapid production protocol was developed. The high concentration of the sucrose exhibited major role for hyphal growth and spore development in in vitro production of $R$. irregularis and maltose being the least. Among all combinations tested, sucrose $(10 \mathrm{~g} / \mathrm{l})+\mathrm{glucose}(1 \mathrm{~g} / \mathrm{l})$ resulted in well developed mycelial network with profuse spore $(59073 \mathrm{IP} / 100 \mathrm{ml})$ in M medium in 90 days of incubation along with proportional increase in percentage of colonization and root weight. Tri- calcium phosphate did not significantly enhance the spore development, root colonization and root weight. Different concentrations of IAA and IBA combinations did not affect the root weight and spore development.
\end{abstract}

\footnotetext{
Abbreviations: AMF: Arbuscular mycorrhizal fungus; IP: Infective propagules; IAA: Indole-3-acetic acid: IBA: Indole-3-butyric acid; AM: Arbuscular mycorrhiza; MTCC: Microbial type culture collection; M medium: Minimal medium; P: Phosphorous; Ri: Root inducing; T-DNA: Transfer Deoxyribo nucleic acid; ppm: parts per million; R: Rooting hormonal concentration; CS: Carbon source.
}

\section{Introduction}

Arbuscular mycorrhizal fungi (AMF) complete its life cycle by forming the symbiotic association with live plant roots by promoting their growth and protecting from soil borne pathogens (Xavier and Boyetchko, 2002). The establishment of AMF in vitro root organ cultures has greatly influenced the potential for research and large scale production of uninfected inoculum production. In vitro root organ culture system was first reported by White and co-workers (White, 1943; Butcher and Street, 1964; Butcher, 1980). Large scale production of monoxenic AM fungal culture under in vitro root organ culture process is the most promising way to obtain good amount of extraradical spores in a shortest time with contamination free inoculum (Bidondo et al., 2012).

The excised roots on synthetic mineral media supplemented with vitamins and sugar source result in profuse root proliferation, characterized by the formation of numerous branches with small hairy roots with few plant species (Fortin et al., 2002). The formation of hairy roots is essential for the development of vigorous root biomass and establishment of continuous AM fungal cultures. AMF cultivation techniques based on Agrobacterium rhizogenes transformed roots provide the development of the AMF inoculum in vitro (Bécard and Fortin, 1988; Adholeya et al., 2005; Ijdo et al., 2011). After the development of monoxenic cultures of AM 
fungus through root organ culture lead to the continuous observations of fungal colonization and mycelium development as well as the sporulation.

For production of AM fungi in root organ cultures, Tiwari and Adholeya (2002 and 2003) used small containers, in which large-scale production was reported (Adholeya et al., 2005). Later, Gadkar et al. (2006) developed a container with separate compartments having the media to initiate AM fungi and another compartment filled with sterile clay balls by providing the glucose as carbon source for the further growth of the AMF. Fitze et al. (2005) studied the impact of IAA and IBA with amino acids on colonization of AMF in maize.

\section{Materials and methods}

The effects of carbohydrates, tri calcium phosphate, rooting hormones were studied in $\mathrm{M}$ medium. $100 \mathrm{ml}$ of M medium $250 \mathrm{ml}$ glass bottles, actively growing host and sterilized inoculum were required. The host was developed by the transformation (Mugnier and Mosse, 1987) of carrot roots with Agrobacterium rhizogenes (MTCC-532) culture obtained from Microbial type culture collection, Chandigarh, India. Sterilized root clumps were developed for the continuous regeneration of fresh hairy roots and inoculated with Rhizophagus irregularis isolated and identified from Narsapur forest, Telangana state, India.

\section{Effect of different carbon sources}

Based on the previous investigations, a high concentration of sucrose was found to be the limiting factor for endomycorrhizal fungal growth. Different carbon sources (HiMedia, India) like glucose, maltose, arabinose with the combinations of sucrose (Table 1) were used to increase the mycorrhizal colonization, spore formation and for extensive root growth (Table 3). The transformed mycorrhizal infected active root clumps were inoculated into the bottles and incubated in dark at $26 \pm 2^{\circ} \mathrm{C}$ for 90 days.

Table 1. Effect of carbon source on in vitro colonisation, root weight and spore count in Rhizophagus irregularis.

\begin{tabular}{|c|c|c|c|c|c|}
\hline Test & Name of carbohydrate & $\begin{array}{l}\text { Quantity/ } \\
\text { Concentration in g/l }\end{array}$ & $\begin{array}{l}\text { Root weight in } \\
\text { grams }\end{array}$ & $\begin{array}{l}\% \text { of } \\
\text { colonization }\end{array}$ & Spore count \\
\hline $\mathrm{CS}-2$ & Glucose & 10 & $2.34 \pm 0.45^{\mathrm{c}}$ & $61.9 \pm 1.37^{\mathrm{e}}$ & $21956 \pm 1477.7^{f}$ \\
\hline CS-4 & Sucrose + Glucose & $10+5$ & $3.60 \pm 0.19^{\mathrm{a}}$ & $83.6 \pm 1.58^{\mathrm{a}}$ & $56649 \pm 2107.2^{b}$ \\
\hline CS-5 & Sucrose + Glucose & $5+10$ & $2.67 \pm 0.13^{c}$ & $73.3 \pm 1.77^{d}$ & $28305 \pm 980.6^{\mathrm{d}}$ \\
\hline CS-7 & Sucrose + Glucose & $10+1$ & $3.46 \pm 0.18^{\mathrm{a}}$ & $83.1 \pm 1.45^{\mathrm{a}}$ & $59073 \pm 1568.0^{a}$ \\
\hline CS-8 & Sucrose + Arabinose & $10+1$ & $3.30 \pm 0.18^{b}$ & $80.3 \pm 1.25^{\mathrm{c}}$ & $55889 \pm 861.50^{a}$ \\
\hline
\end{tabular}

Data indicate mean \pm standard error of the 20 replicates per treatment in three repeated experiments. Mean followed by the same letter was not statistically significant at $0.05 \%$ probability.

\section{Effect of tri-calcium phosphate}

In M-medium, potassium di-hydrogen phosphate, a phosphorous source was replaced with insoluble tricalcium phosphate. To study the effect of AMF solubilisation and transport unavailable phosphorous to the plant roots, different concentrations of tri-calcium phosphate as phosphorus source i.e., $1 \mathrm{mg} / \mathrm{l}(\mathrm{P}-1), 5 \mathrm{mg} / \mathrm{l}$ (P-2), $25 \mathrm{mg} / \mathrm{l}(\mathrm{P}-3)$ and $50 \mathrm{mg} / \mathrm{l}(\mathrm{P}-4)$ were studied in $\mathrm{M}$ medium with $1 \%$ of sucrose and $5.6 \mathrm{pH}$ on root growth, mycorrhizal colonization and spore formation and compared with control in $\mathrm{M}$ medium. The transformed mycorrhizal infected active root clumps were inoculated into the bottles and incubated in the dark at $26 \pm 2^{\circ} \mathrm{C}$ for 90 days.

\section{Effect of rooting hormones on transformed roots}

For mass production of mycorrhizal spores, root growth also plays an important role. In addition to transformation, effect of synthetic hormones application at different concentrations to enhance the root growth were studied on transformed carrot roots (Table 2). For the development of endomycorrhiza, vigorously growing plant roots are essential. For getting the vigorous root growth hormones play crucial role. To avoid the usage of rooting hormones, roots were transformed with Ri-T DNA. To study the effect of root inducing plasmid with regular rooting hormones, different concentrations of IAA and IBA were studied on root growth and percentage of mycorrhizal colonization on transformed carrot root clumps. 


\section{Results and discussion}

Agrobacterium rhizogenes MTCC-532 strain successful transformation was made and developed transformed callus root clumps. The callus root clumps were inoculated with Rhizophagus irregularis and got the infected callus root clumps with fresh hairy roots.
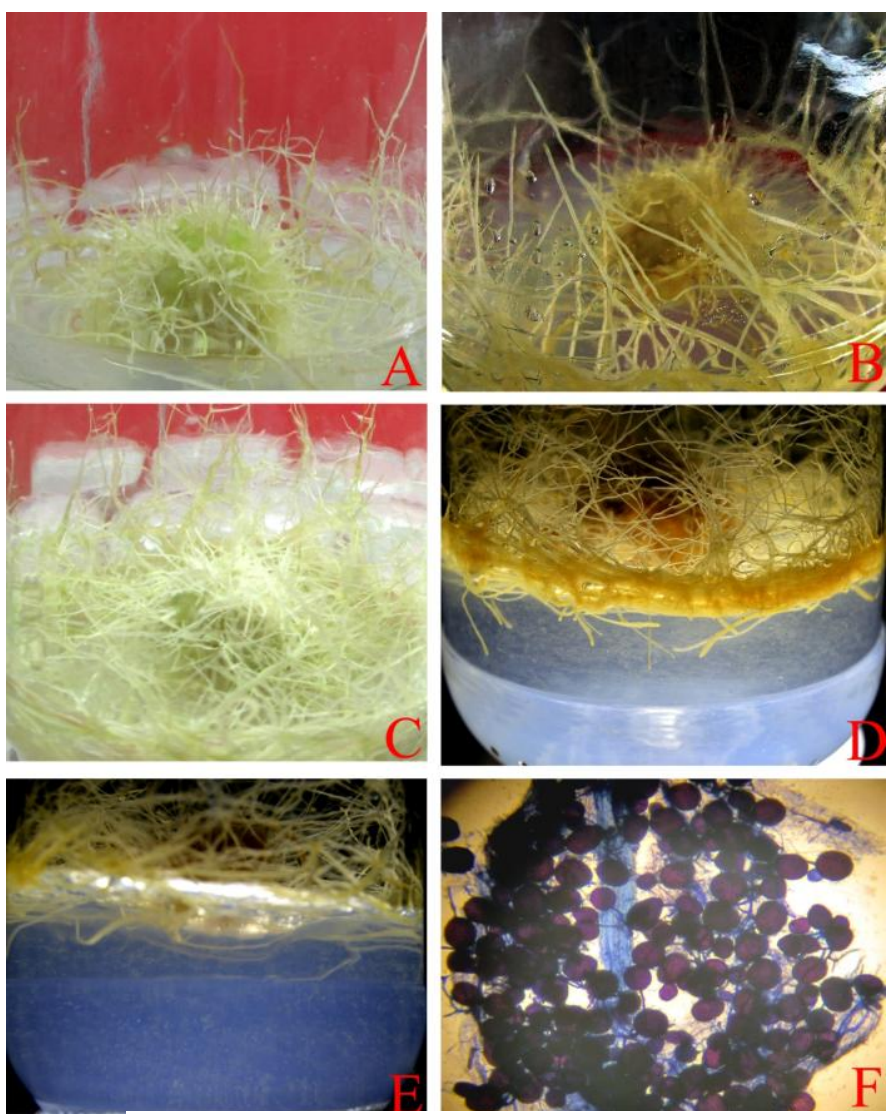

Fig. 1: Effect of carbon source, IAA and IBA on in vitro colonisation, root weight and spore count in Rhizophagus irregularis. (A) Transformed root clumps showing many fresh hairy roots supplemented with $1 \%$ Glucose (CS-1) containing M medium; (B) Extended root growth from the transformed callus root clumps in general $\mathrm{M}$ medium; (C) Extensive root growth from the clumps supplemented with $1 \%$ sucrose and $0.1 \%$ glucose (CS-7) in M medium; (D) Profuse spore development with extensive mycelium developed from the roots in CS-7 combination of $\mathrm{M}$ medium; (E) Minimum spore development in glucose supplemented $\mathrm{M}$ medium; (F) Extensive intraradical spore development observed in trypan blue staining in CS-7.

AMF hyphae utilize the glucose from the host plant (Shachar-Hill et al., 1995; Solaiman and Saito, 1997) and reducing sugars like glucose, sucrose and fructose (Demir, 2004). With the replacement of sucrose in M medium with glucose, more number of fresh hairy roots were observed within 5 days of incubation (Fig. 1a) but not grown extensively and with much less development of spores (21956 IP) in CS-2 (Fig. 1e). In sucrose alone (CS-1) containing medium, development of fresh hairy roots was moderate but supported root growth (3.35 g), root colonization $(81 \%)$ and extensive spore formation (55407 IP).

After 30 days of incubation, sucrose containing bottles has shown extended root growth than the glucose bottles (Fig. 1b). The combination sucrose and glucose in CS-4 and CS-7 were shown maximum root colonization (Figs. 1c and 1d) and higher spore formation than in CS-5 and CS-6. Profuse root growth, colonization and spore formation were observed in CS-1, CS-4, CS-7 and CS-8. Among all, $1 \%$ sucrose with $0.1 \%$ glucose (CS-7) showed $3.46 \mathrm{~g}$ of root weight, $83.1 \%$ colonization (Fig. 1f) and 59073 IP count. Maltose and arabinose did not show any significant positive results in the formation of roots, root colonization and spore development (Table 1). The combination of arabinose with sucrose gave good results like CS-1.

Tri-calcium phosphate is insoluble in water. It can be solubilise with the help of organic acids produced by phosphate solubilizers (Ordonez et al., 2016). Mycorrhiza can transport the phosphorous to the plants with synergetic affect with soil microbes (Bagyaraj et al., 2015). To study the impact of AMF on phosphate solubilisation, potassium di-hydrogen phosphate was replaced with tri-calcium phosphate in $\mathrm{M}$ medium. But the newly added phosphate source i.e., tri-calcium phosphate did not show any significant positive results in spore production and root colonization. The formation of spores was somewhat bigger than the normal root organ culture spores, but the spore count was very less and root colonization was also very poor. In P-1 percentage of root colonization was less (35.7\%) than P-3 $(45.5 \%)$ but spore development was more in P1 (25089 IP) than P-3 (12418 IP). The spore development was significantly decreased but root growth was increased with increasing of tri- calcium phosphate concentration. The results showed that Rhizophagus irregularis was not significantly solubilise the tri-calcium phosphate (Table 2) and the development of regular root growth was also limited. The results showed that AMF do not have the capability to solubilise the tri- calcium phosphate like phosphate solubilising bacteria or fungi.

According to Fitze et al. (2005) conjugation of IAA and IBA with amino acids and sugars enhance the colonization in maize roots. Based on this study, the impact of IAA and 
IBA in different concentrations on Ri-T DNA transformed callus root clumps was studied to enhance root growth and percentage of colonization and spore development. The individual concentrations and combination of IAA and IBA did not significantly enhance the root growth and spore development when compared to control. Almost all the concentrations showed the same results in the development of spore formation (Table 3). The results revealed the fact that regular rooting hormones would not have significant impact on transformed roots.

Table 2. Effect of potassium di-hydrogen phosphate and tri-calcium phosphate on in vitro colonisation, root weight and spore count Rhizophagus irregularis.

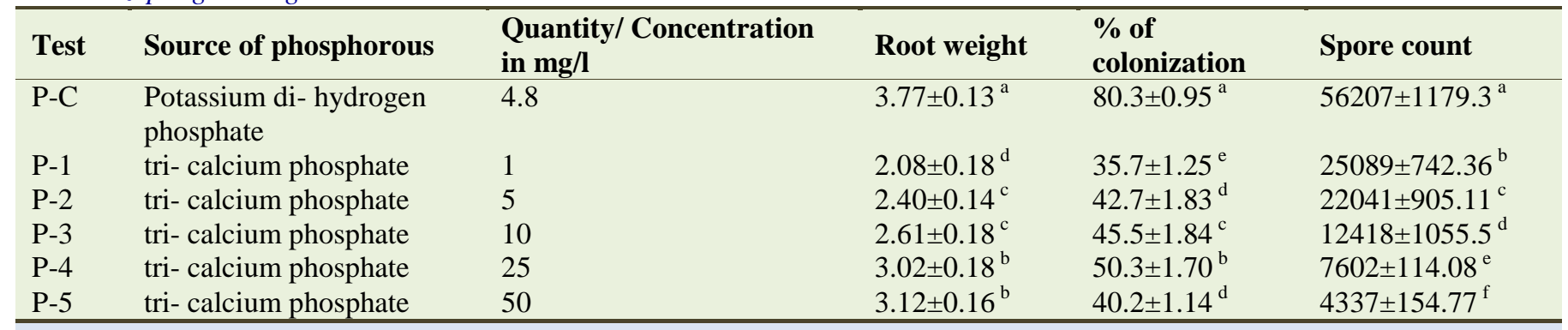

Data indicate mean \pm standard error of the 20 replicates per treatment in three repeated experiments. Mean followed by the same letter was not statistically significant at $0.05 \%$ probability.

Table 3. Effect of IAA and IBA on in vitro colonisation, root weight and spore count in Rhizophagus irregularis.

\begin{tabular}{|c|c|c|c|c|c|c|}
\hline S. No & Test name & $\begin{array}{l}\text { IAA in } \\
\mathrm{ppm} / \mathbf{l}\end{array}$ & $\begin{array}{l}\text { IBA in } \\
\mathrm{ppm} / \mathbf{l}\end{array}$ & Root weight & $\%$ of colonization & Spore count \\
\hline 1. & R 0 & Nil & Nil & $3.39 \pm 0.15^{\mathrm{d}}$ & $82.6 \pm 1.17^{\mathrm{a}}$ & $57719 \pm 1151.8^{a}$ \\
\hline 2. & R 1 & 250 & Nil & $3.21 \pm 0.12^{\mathrm{d}}$ & $81.2 \pm 1.03^{b}$ & $55845 \pm 996.18^{\mathrm{c}}$ \\
\hline 4. & R 3 & 1000 & Nil & $3.63 \pm 0.11^{b}$ & $80.8 \pm 1.31^{\mathrm{b}}$ & $55585 \pm 1297.3^{c}$ \\
\hline 5. & R 4 & Nil & 250 & $3.49 \pm 0.18^{c}$ & $81.9 \pm 1.73^{b}$ & $56630 \pm 968.14^{b}$ \\
\hline 6. & R 5 & Nil & 500 & $3.57 \pm 0.20^{b}$ & $82.5 \pm 1.51^{\mathrm{a}}$ & $57061 \pm 989.83^{a}$ \\
\hline 8. & R 7 & 50 & 50 & $3.69 \pm 0.15^{b}$ & $80.3 \pm 1.25^{c}$ & $56289 \pm 839.78^{b}$ \\
\hline 9. & R 8 & 250 & 250 & $3.82 \pm 0.13^{a}$ & $79.9 \pm 0.74^{\mathrm{d}}$ & $54949 \pm 939.91^{\mathrm{c}}$ \\
\hline 10. & R 9 & 500 & 500 & $3.56 \pm 0.14^{\mathrm{a}}$ & $81.2 \pm 1.14^{\mathrm{b}}$ & $56031 \pm 1395.6^{b}$ \\
\hline
\end{tabular}

Data indicate mean \pm standard error of the 20 replicates per treatment in three repeated experiments. Mean followed by the same letter was not statistically significant at $0.05 \%$ probability.

\section{Conflict of interest statement}

Authors declare that they have no conflict of interest.

\section{Acknowledgement}

The authors are thankful to Sri GVSSR Anjaneyulu, Chairman, Shivashakti group of companies; Smt. G. Leelavathi, Chairperson, Sri N. Srinivasa Rao, Managing Director, Sri K.N. Rao, Director for their encouragement and for providing facilities to carry out the research work.

\section{References}

Adholeya, A., Tiwari, P., Singh, R., 2005. Large-scale production of arbuscular mycorrhizal fungi on root organs and inoculation strategies. In: In Vitro Culture of
Mycorrhizas (Eds.: Declerck, S., Strullu, D. G., Fortin, J. A.). Springer, Heidelberg. pp.315-338.

Bagyaraj, D.J., Sharma, M.P., Maiti, D., 2015. Phosphorus nutrition of crops through arbuscular mycorrhizal fungi. Curr. Sci. 108(7), 1288-1293.

Becard, G., Fortin, A., 1998. Early events of vesicular arbuscular mycorrhiza formation on $R i$ T-DNA transformed roots. New Phytol. 2, 211-218.

Bidondo, L. F., Pergola, M., Silvani, V., Colombo, R., Bompadre, J., Godeas, A., 2012. Continuous and longterm monoxenic culture of the arbuscular mycorrhizal fungus Gigaspora decipiens in root organ culture. Fungal Biol. 116, 729-735.

Butcher, D.N., Street, H.E., 1964. Excised root culture. Bot. Rev. 30, 513-586.

Butcher, D.N., 1980. The culture of isolated roots. In: Tissue Culture Methods for Plant Pathologists (Eds.: Ingram, D.S., Helgelson, J.P.). Blackwell Scientific, Oxford. pp.13-17.

Demir, S., 2004. Influence of arbuscular mycorrhiza on some 
physiological growth parameters of pepper. Turk. J. Biol. $28,85-90$.

Fitze, D., Wiepning, A., Kaldorf, M., Ludwig-Muller, J., 2005. Auxins in the development of an arbuscular mycorrhizal symbiosis in maize. J. Plant Physiol. 162, 1210-1219.

Fortin, J.A., Becard, G., Declerck, S., Dalpe, Y., St-Arnaud, M., Coughan, A.P., Piche, Y., 2002. Arbuscular mycoorhiza on root-organ cultures. Can. J. Bot. 80, 1-20.

Gadkar, V., Driver, J.D., Rillig, M.C., 2006. A novel in vitro cultivation system to produce and isolate soluble factors released from hyphae of arbuscular mycorrhizal fungi. Biotechnol. Lett. 28, 1071-1076.

Ijdo, M., Cranenbrouck, S., Declerck, S., 2011. Methods for large scale production of AM fungi: Past, present, and future. Mycorrhiza. 21, 1-16.

Mugnier, J., Mosse, B., 1987. Vesicular-arbuscular infections in $R i$ T-DNA transformed roots grown axenically. Phytopathol. 77, 1045-1050.

Ordonez, Y.M., Fernandez, B.R., Lara, L.S., Rodriguez, A., Uribe-Velez, D., Sanders, I. R., 2016. Bacteria with phosphate solubilizing capacity alter mycorrhizal fungal growth both inside and outside the root and in the presence of native microbial communities. PlosOne. 11(6), e0154438.

Shachar-Hill, Y., Pfeffer, P.E., Douds, D., Osman, S.F., Doner, L.W., Ratcliffe, R.G., 1995. Partitioning of intermediary carbon metabolism in vesicular arbuscular mycorrhizal leek. Plant Physiol. 108, 7-15.

Solaiman, M.D., Saito, M., 1997. Use of sugars by intraradical hyphae of arbuscular mycorrhizal fungi revealed by radiorespirometry. New Phytol. 136, 533-538.

Tiwari, P., Adholeya, A., 2002. In vitro co-culture of two AMF isolates Gigaspora margarita and Glomus intraradices on $R i$ T-DNA transformed roots. FEMS Microbiol. Lett. 206(1), 39-43.

Tiwari, P., Adholeya, A., 2003. Host dependent differential spread of Glomus intraradices on various $R i$ T- DNA transformed roots in vitro. Mycol. Prog. 2, 171-177.

White, P.R., 1943. A Handbook of Plant Tissue Culture. The Jaques Cattell Press, Lancaster, Pennsylvania.

Xavier, I.J., Boyetchko, S.M., 2002. Arbuscular mycorrhizal fungi as biostimulants and bioprotectants of crops. Appl. Mycol. Biotechnol. 2, 311-330.

\section{How to cite this article:}

Mohan Raj, B., Bharath Kumar, R., Venkata Rao, G., Sri Rama Murthy, K., 2016. Impact of different carbon sources, tri-calcium phosphate and auxins on in vitro multiplication of Rhizophagus irregularis. Int. J. Curr. Res. Biosci. Plant Biol. 3(7), 162-166. doi: http://dx.doi.org/10.20546/ijcrbp.2016.307.022 